\title{
Menopause, A Symptom of Change!
}

\author{
Utkarsha Malkar* \\ ISDI Indian School of Design \& Innovation, India
}

\begin{abstract}
India. However, the impact of patriarchal structure reigns over every aspect of a women's existence in Asia. From health and education to simple neglect in all aspects social or religious. From shaming the menstrual cycle to ignoring her menopausal cries for help, women are subjected to many pervasive discriminations. Gender bias exists in all rural and urban societies as a women's wellbeing takes a backseat as she is not considered the prime provider for the family unit. Many women are not even aware of the symptoms of menopause. Symptoms are treated as a disease! A methodical approach whereby women across the spectrum of society were interviewed along with with their family members to get first-hand insight on women health-related issue in urban India. Secondary data was gathered through interviews conducted with medical practitioners and other free resources available on the world wide web. An urban-based campaign is designed within the academic parameters of Communication Design at ISDI, which seeks to educate society and women at large about the changes that can occur both on the conscious and subconscious level and how to deal with them. A holistic approach whereby educating society at large on a topic not discussed openly as society is handicapped by the male customized versions of "it being a women's problem only"! Targeting this issue will benefit women in India and change mindsets of a regressive society which needs to address women related issues by adopting a healthy attitude.
\end{abstract}

Keywords: women rights, menopause, social Communication, urban India, patriarchy

Pause...

Even as the urban women in India in their forty somethings find themselves in the 19th year of the 3rd millennium and the 19th year of the 21st century, and the 10th and last year of the 2010's decade enjoying relative freedom compared to their sisters in rural India...we are all equalized by the age-old symptoms of (*MENOPAUSE) and its consequences. (*Pun Intended).

A male dominated society which perpetuates intellectual bankruptcy and thrives on patriarchal traditions with a distaste for abstract reasoning does not even see "Menopause" as an issue of concern for society at large. Men predominate the Indian Society hence women are invariably the victims of humiliation, torture and exploitation. Discrimination in society is an acceptable norm and at times we witness women themselves perpetuating this tradition by not lending a supportive stance, a perfect example would be the age-old feud between the mother and daughter in-law which is in fact celebrated through popular media and entertainment industry. This only lends to weaken women's psyche as she finds no support or sympathy within her tribe.

A male dominated society which perpetuates intellectual bankruptcy and thrives on patriarchal traditions with a distaste for abstract reasoning does not even see "Menopause" as an issue of concern for society at large.

It lays one-sided emphases on a family as a male led unit and it begins with psychological premise that it is the wellbeing of the male offspring and later the man of the house, and that's something that must not be overlooked inasmuch as they overstress that element and ignore or deny the others, they end up with a truncated and thereby oppressive vision of the women and their place in this society.

Their skepticism toward any knowledge on women related issue dictates and thrives from the imbalance both economic and social. In the modern bourgeois society all relations are subordinated as commercial equation is practiced, however even this theory does not apply to a woman contributing to the economy and battling the many symptoms of Menopause'. Objective of this Communication Design campaign is to educate people in an 
engaging and creative way where they can at a conscious level embrace the change and be ready for a open dialogue within society and within their homes. To change human perceptions, where the psychological structure of society seems to be modified almost far beyond any chances of it will ever seeing women as human beings or rather as beings who have 'women related problems!

This Campaign is based at a hypothetical level as an academic exercise where many issues concerning society are raised. A creative solution is sought as a direct approaches in sensitive matters seldom works in a society still struggling with discussing menstruation or any other issue related to women in general.

Many interviews were conducted across various sections of society and it was alarming that in urban setting, the most cosmopolitan city in the country there seemed to be a mask over this issue. There seemed to be hesitance as well as denial of the structure of reality. The lack of support system from both within the family unit and society at large led to a logical analysis which exhibits the true nature of modern society which holds on to its medieval values. As creative academia our mission is to represent facts by mirroring society in its natural language statements. As knowledge can be transmitted neither as true or false knowledge but by description of facts. It can be inferred in more than one way, as a result of acquaintance with the world at large those aspects of the world make the corresponding propositions true. We have approached the Menopause Society of India and also looked for prospective sponsors who would be willing to release the campaign on social media or large format as showcased here in the creatives. The aim is to over time empower women subjugated over centuries, denied of natural rights and the fact that truth can be accessed through inference and an open dialogue is one more step towards picturing reality and hopefully changing it.

Facts: [1] [2] Menopause is documented as a complete cessation of menstruation for a period of 1 year. Perimenopause duration is variable, and it is defined as the time of irregular periods until menopause. The natural menopausal age of a woman serves as a biomarker for subsequent disease prediction and mortality. [3] $125,873,412$ number of women are going through menopause in India.

[4] Menopause is the time in a woman's life when her period stops. It usually occurs naturally, most often after age 45. [5] Menopause happens because the woman's ovaries stop producing the hormones estrogen and progesterone. A change in periods - shorter or longer, lighter or heavier, hot flashes and/or night sweats, trouble sleeping, vaginal dryness, mood swings, trouble focusing, Less hair on head, more on face. While earlier menopause is associated with an increased risk of cardiovascular disease and osteoporosis. Epidemiological studies have identified that age-adjusted mortality is reduced by $2 \%$ while the risk of uterine/ovarian cancer increases by $5 \%$ with each increasing year of age at menopause. Some symptoms require treatment. Risk factors are chances for heart disease, osteoporosis, or breast cancer increase.

Communication Design as a discipline engages with topics of relevance for society at large. The aim of this campaign is practical within the academic parameters and it tries to open a space for dialogue in a society where women issues are seldom discussed openly except at women led forums and now perhaps on Netflix Indian Original, this campaign seeks to reach out to a larger audience to both sensitize them and educate them and hopes to see the change in society that could make a qualitative difference for generations to come.

\section{Let's talk...}

Targeted at urban clinics in association 'Indian Menopause Society' it brings to light a topic which needs to be discussed openly in society minus its inhibitions.

The tone of the campaign is conversational but deliberate, as the targeted audience are primarily 'Men / Husbands, who are educated along with their spouses on what 'Menopause is...They are encouraged to seek medical assistance provided by the Indian Menopause society, an organization dedicated to this cause. 
This campaign if run over a period of several months can create within society an acceptance to open up discussion on this topic and lead to wider acceptance of a problem always viewed as a 'women related issue' not of consideration for a 'larger society' where women play many roles as wives, mothers and homemakers contributing to the economy at large and single units of families which are a part of the very society which in turn is the nation and the entire subcontinent.

\section{Is it that time of the month?}

A pervasive attitude adopted by men affirming it's that time of the month for women when they are not submissive or agreeable! The creatives are almost a teaser, very strong and impactful. A twist in the tone when it suggests a popular notion of it being a mood swing or vaginal dryness or even a headache. It clearly emphasizes that it's not that time of the month nor is it a tantrum and nor does she have a headache! It's a clear call to action by stating the facts that it's a symptom of change and expects the audience to get alarmed to a certain extent. A bold approach in a conservative society could ignite the spark of a movement towards taking steps to voice this issue of concern of a half the population within the country.

If we get success on the onset of this movement, it would be by no means a small achievement. It would be a small step towards working on collective psyche of generations of the male dominated society to look at women with the respect they deserve as the bearer of the species and not the weaker reproducer who can be discarded when not of further benefit to a unit due to their temporary disposition.

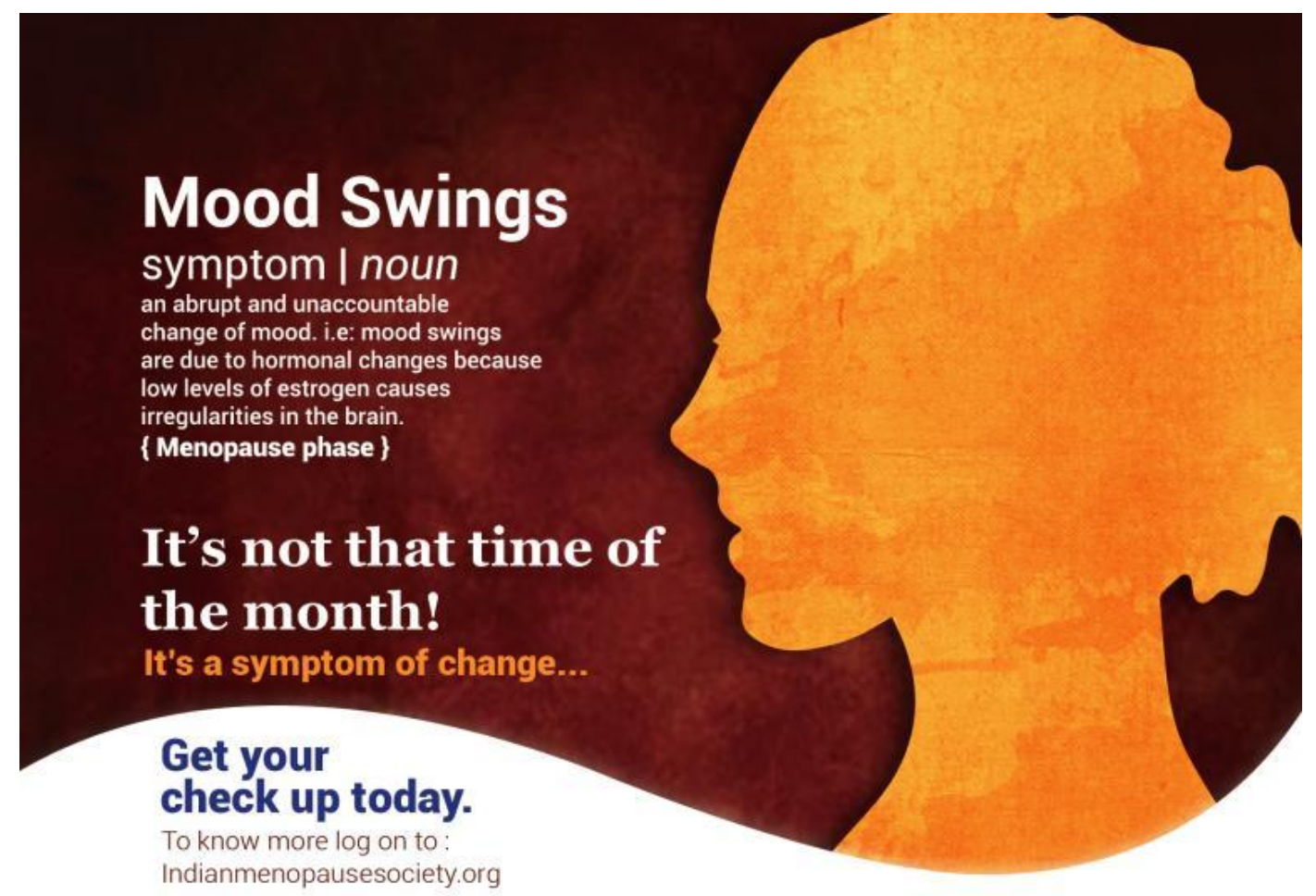

Figure 1 :The eye-catching Mood Swings Typo, followed by its dictionary explanation...changes tone as it gives a hint that it could be more serious than that. Getting your check up today is a direct call to action hoping that the audience will take the necessary steps. It is meant to target both the men and women who can understand the subtext.

\section{Is it that time of the month?}

Women, who hopefully with this campaign and many such platforms can actually ask for their rights to a support system which accepts and understands the needs of women's being needs of a human being who is not a man but has equal rights to be treated with empathy and respect. 


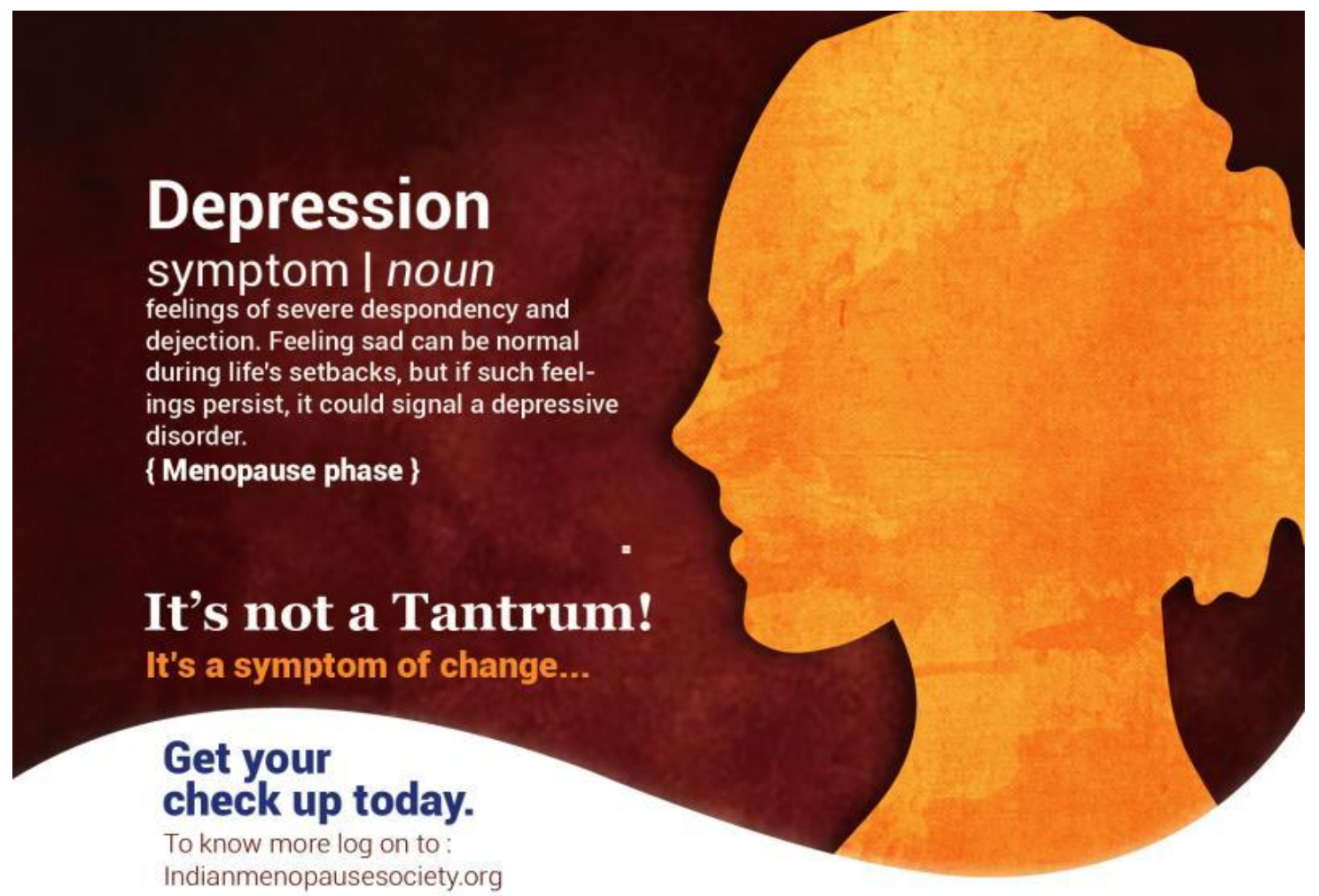

Figure 2 Depression which seems to be a common denominator catches the concern of the audience. The dictionary explanation gives clarity and tries to build empathy. The fact that women are not throwing a tantrum, but it is one of the symptoms of menopause and needs to be looked at holistically. The symptom of change is reinforced in typo and the need to get your checkup is always the primary goal.

\section{It's a symptom of change...}

A print and digital based campaign creating awareness amongst urban women and their family members, to help them understand that 'Menopause' is a changing phase of a woman's life...

Having tested the campaign with many women who could identify with the symptom's felt that this creative campaign could lead to an open dialogue in society and women could speak about this particular issue without hesitation and not suffer in silence like past generations who have gone to their graves unceremoniously accused of anything from mental illness to misbehavior. A primary cause of marital discord in some cases leading to divorce and in worst cases to suicide. Here's hoping the campaign reaches a larger audience across the Asian sub-continent and receives the attention it deserves thereby enabling women and men to deal with this issue with due diligence and seriousness it deserves.

What we hope to achieve via a print-based campaign at strategic locations like clinics and hospitals is small steps towards engaging society and making it a better place for women! It may not ever or always be possible to attain this equilibrium. But we can always have it as our constant goal and seek to evaluate all that we and others say and do in this vital area. A healthy approach adopted by our study will lead to a healthy woman and a healthy society. 


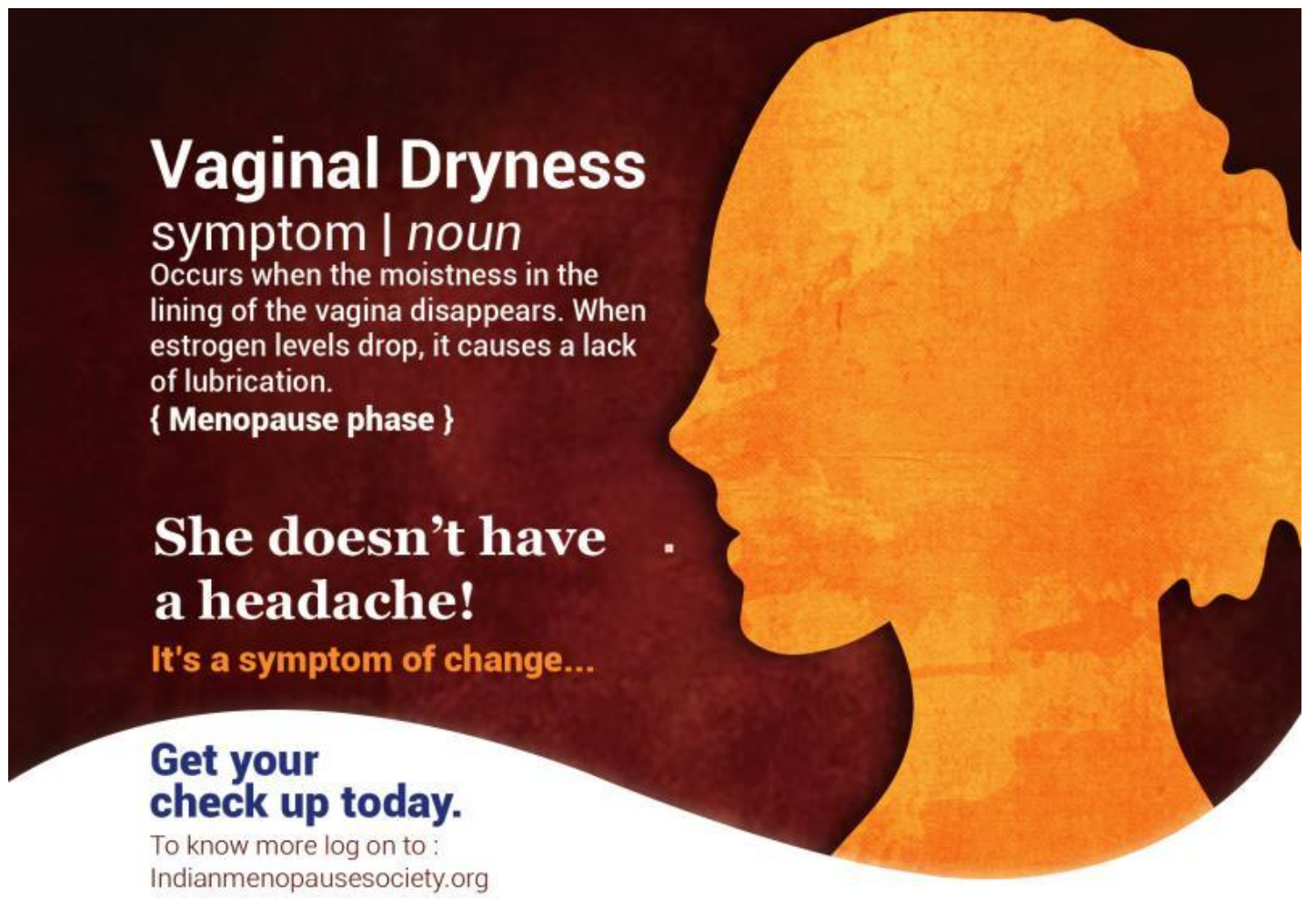

Figure 3 Headache? Not really, as the sexual urge declines and women try not to get intimate it is a problem that the couple needs to tackle with sensitivity. The onset of Menopause and its side effects can be driven home very clearly with this creative.

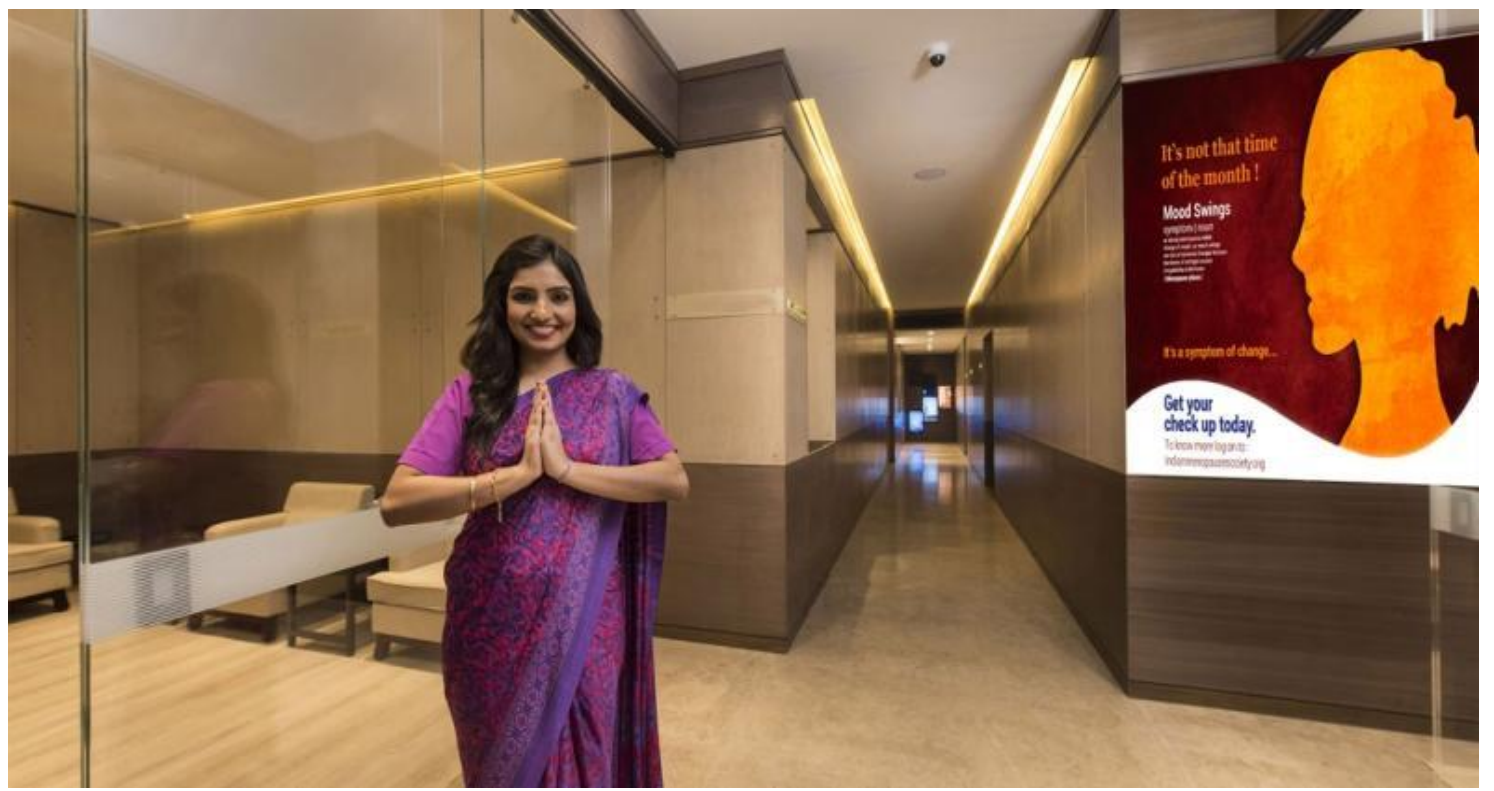

Figure 4 A mockup of how the creative campaign can be used on large format public display. The need to be seen is eminent as this issue can no longer be a women's issue but needs the participation of the society including its male members who are husbands and play a pivotal role by giving it the attention it deserves.

Disclaimer: All creatives are hypothetical class room projects by 'HARSHINA SODHANI' - 2018-2019. All rights reserved ISDI. About the Institute: ISDI is committed to a new model of cutting-edge design and innovation education, integrated with commercialization of design. The ISDI method of pedagogy is based on 
intensive specialization built on strong fundamentals of liberal arts, critical thinking, skill training and master classes.

Creativity, innovation and sustainability form the core of ISDIology. ISDI brings about an Indianization' of global innovations while working out a global perspective to Indian innovations.

\section{References}

[1 Internet source] https://www.womenshealth.gov/menopause | https://www.menopause.org/

[2 Internet source] https://medlineplus.gov/menopause.html (brief about menopause, symptoms, test.) http://www.myfreelady.com

[3 Internet source] https://draxe.com/5-natural-remedies-menopause-relief/

http://www.jmidlifehealth.org/article.asp?issn=0976-

7800 ; year $=2016$; volume $=7$; issue $=3$; ;page $=126$; epage $=131$; aulast $=$ Ahuja

[3 Internet source] https://www.mayoclinic.org/diseases-conditions/menopause/symptoms-causes/syc-20353397 https://www.webmd.com/menopause/guide/menopause-basics\#1

[4 Internet source] http://menopause.northwestern.edu/content/stages-menopause https://epostersonline.com/ims2018/node/156

[5 Internet source] http://www.ijmr.org.in/article.asp?issn=09715916; year $=2016$; volume $=144 ;$ issue $=3$; spage $=366$; page $=377$; aulast $=$ Pallikadavath

YouTube Links

https://www.youtube.com/user/durushah

https://www.youtube.com/watch?v=Lwxf_3vIoQ4

https://www.youtube.com/channel/UC-4OHO-C2exmMFhKwVFgX6A

https://www.youtube.com/watch?v=hiQ813OVSYE

https://www.youtube.com/watch?v=U8UWOuOjZ-4 